other evidence - that the vaccine does not trigger autism. But they could complicate the debates about Wakefield's integrity and the UCL investigation.

The documents that Lewis reviewed include confidential forms describing biopsies from the guts of children. The forms were filled out by pathologists Andrew Anthony and Paul Dhillon, who worked with Wakefield at the Royal Free. These documents, Lewis says, are relevant to Deer's charge that records he obtained do not support Wakefield's claims in the Lancet paper that the children had nonspecific colitis, a supposed element of an MMRinduced syndrome. On sheets for three of the children graded by Anthony, the handwritten word "colitis" appears, and Dhillon checked a box labelled "non-specific" on 10 forms. Anthony's sheets are dated after the Lancet publication, whereas Dhillon's are dated before.

Lewis believes that the sheets show that Anthony and Dhillon were making good-faith diagnoses of colitis. Anthony, who has left UCL, could not be reached by Nature, and Dhillon indicated that UCL had told him not to comment. (Neither has been accused of manipulating data.)

Before publishing Lewis's letter, the $B M J$ asked Ingvar Bjarnason, a gastroenterologist at King's College Hospital, London, to review the materials. Bjarnason says he doesn't believe they are sufficient to support claims in the Lancet paper of a new disease process. He also questions whether "non-specific" on the grading sheets refers to colitis, saying it could refer to any kind of gut changes. But he says that the forms don't clearly support charges that Wakefield deliberately misinterpreted the records. "The data are subjective. It's different to say it's deliberate falsification," he says.

Deer notes that he never accused Wakefield of fraud over his interpretation of pathology records. But he says that records read to him from the Royal Free pathology service clearly stated that the children's gut biopsies were within normal limits, even though they were reported in the Lancet paper as having enterocolitis.

Fiona Godlee, the editor of the BMJ, says that the journal's conclusion of fraud was not based on the pathology but on a number of discrepancies between the children's records and the claims in the Lancet paper. She says she will be calling for a public inquiry into the matter, noting that it has been more than a year since she first informed UCL about concerns over Wakefield's work.

Wakefield denies charges of data manipulation. He says that UCL has yet to officially request his response to any charges and he isn't convinced that the inquiry will give him a fair hearing. A UCL spokesman says that the investigation will be "thorough, fair and wideranging". But eight months after announcing its inquiry, the university is still looking for a suitable external chairman.

TECHNOLOGY

\title{
Time is running out for the leap second
}

\section{Abolition would see 'official' time unmoored from the Sun.}

\section{BY ZEEYA MERALI}

CC The times," sang Bob Dylan, "they are a-changin'." His words could become literal truth in January, when the World Radiocommunication Conference of the International Telecommunication Union in Geneva, Switzerland, will vote on whether to redefine Coordinated Universal Time (UTC) and pull our clock time out of synchronization with the Sun's location in the sky.

At issue is whether to abolish the 'leap second' - the extra second added every year or so to keep UTC in step with Earth's slightly unpredictable orbit. UTC - the reference against which international time zones are set - is calculated by averaging signals from around 400 atomic clocks, with leap seconds added to stop UTC drifting away from solar time at a rate of about one minute every 90 years.

But "leap seconds are a nuisance", says Elisa Felicitas Arias, the director of the Time Department at the International Bureau of Weights and Measures (BIPM) in Sèvres, France. They cannot be preprogrammed into software because they are typically announced only six months in advance by the International Earth Rotation and Reference Systems Service in Frankfurt, Germany. If the seconds get implemented inconsistently in different systems, clocks can briefly go out of synch, potentially leading to glitches that can stall computers and leave international financial markets vulnerable to attack.

Still, some countries - principally China, Canada and the United Kingdom - want to keep leap seconds to maintain the link with solar time, in part for philosophical reasons. "Most Chinese scholars think it is important for timekeeping to have a connection to astronomical time because of traditional Chinese culture," says Chunhao Han of the Beijing Global Information Center of Application and Exploration, who adds, however, that China has yet to decide how it will vote in January.

Last week, scientists and government representatives met at the Kavli Royal Society International Centre near Milton Keynes, UK, to discuss the issue, but they failed to reach a consensus, making the outcome of the January vote hard to predict. Arias, who co-organized that meeting, argues that leap seconds are obsolete now that global navigation systems, which set their own internal timescales, have replaced solar time for navigation and precision scientific measurements such as the motion of tectonic plates and how Earth's mass warps space-time.

Adding an extra second inconsistently to

multiple clocks across satellite networks could cause a system to fail for long enough to cause an air disaster, says Włodzimierz Lewandowski, a physicist at the BIPM. The US Global Positioning System ignores leap seconds for just this reason, and Russia's GLONASS system has had problems in the past incorporating the leap. Europe's Galileo system, which launched its first two satellites last month, and China's developing BeiDou system will also mark time with their own internal clocks.

But Markus Kuhn, a computer scientist at the University of Cambridge, UK, says that most problems could be overcome by having a consistent prescription for adding extra seconds. Linux operating systems, for example, have experienced problems because they add the whole second in one abrupt jump at midnight, which confuses the software. In September, Google announced that it would use an alternative 'soft-leap' strategy, in which operating systems add portions of the second smoothly over an extended

"There's no convincing evidence that anything serious would happen if you made a mistake introducing $a$ leap second." period. "This should be the standard approach," says Kuhn.

Peter Whibberley, a physicist at the National Physical Laboratory in Teddington, UK, says that despite ten years of debate, "there's no convincing evidence that anything serious would happen if you made a mistake introducing a leap second into a system". Abolishing leap seconds only defers any problems, he adds. "A century down the line, we'll need to introduce a 'leap minute, and nobody has any sensible arguments for why that won't be a worse issue." - 